This article was downloaded by: [Tano Posteraro]

On: 30 October 2014, At: 12:48

Publisher: Routledge

Informa Ltd Registered in England and Wales Registered Number: 1072954

Registered office: Mortimer House, 37-41 Mortimer Street, London W1T 3J H, UK

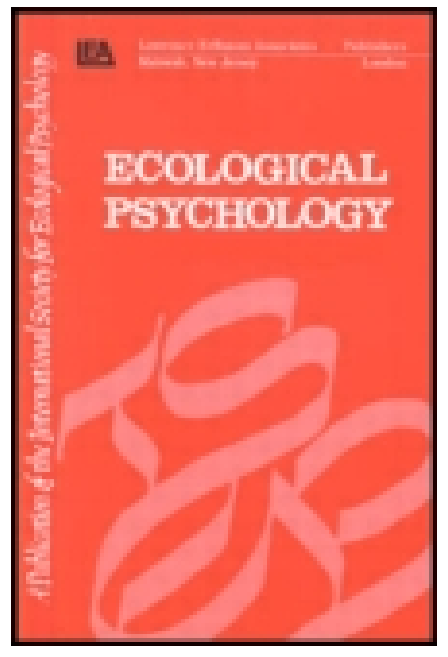

\title{
Ecological Psychology
}

Publication details, including instructions for authors and subscription information: http:// www. tandfonline.com/loi/heco20

\section{On the Utility of Virtuality for Relating Abilities and Affordances}

Tano S. Posteraro ${ }^{\mathrm{a}}$

a Department of Philosophy McMaster University, Canada

Published online: 28 Oct 2014.

To cite this article: Tano S. Posteraro (2014) On the Utility of Virtuality for Relating Abilities and Affordances, Ecological Psychology, 26:4, 353-367, DOI: $10.1080 / 10407413.2014 .958039$

To link to this article: http:// dx.doi. org/ 10.1080/ 10407413.2014.958039

\section{PLEASE SCROLL DOWN FOR ARTICLE}

Taylor \& Francis makes every effort to ensure the accuracy of all the information (the "Content") contained in the publications on our platform. However, Taylor \& Francis, our agents, and our licensors make no representations or warranties whatsoever as to the accuracy, completeness, or suitability for any purpose of the Content. Any opinions and views expressed in this publication are the opinions and views of the authors, and are not the views of or endorsed by Taylor \& Francis. The accuracy of the Content should not be relied upon and should be independently verified with primary sources of information. Taylor and Francis shall not be liable for any losses, actions, claims, proceedings, demands, costs, expenses, damages, and other liabilities whatsoever or howsoever caused arising directly or indirectly in connection with, in relation to or arising out of the use of the Content. 
This article may be used for research, teaching, and private study purposes. Any substantial or systematic reproduction, redistribution, reselling, loan, sub-licensing, systematic supply, or distribution in any form to anyone is expressly forbidden. Terms $\&$ Conditions of access and use can be found at http://www.tandfonline.com/page/terms-and-conditions 


\title{
On the Utility of Virtuality for Relating Abilities and Affordances
}

\author{
Tano S. Posteraro \\ Department of Philosophy \\ McMaster University, Canada
}

\begin{abstract}
This article introduces the concept of virtuality into the question of the ontological status of ability-affordance relations in ecological psychology. By differentiating concrete affordances and animal activities from the somatic-environmental networks they actualize, I argue that ecological-psychological thought is brought into a better position from which to think the ability-affordance relation as a ground for the developmental entanglements of organisms and their subjective environments (i.e., the affordances that constitute their niches). I begin by sketching the aporia to be filled in ecological psychology by an introduction of the virtual. Then, I turn toward a brief elucidation of the concept of virtuality. In the terms developed here, abilities and affordances together comprise a virtual meshwork or field of dynamically linked rates of change, capacities, and tendencies that are actualized or instantiated in terms of individual instances of organismic behavior, environmental configuration, and coevolution. Armed with these conceptual tools, I endeavor, in the article's final section, to provide in terms of virtuality a properly genetic analysis of the dynamic reciprocity between organismic abilities and the recursive configuration of their subjective worlds (or fields of affordances) without recourse to teleological functions, hylomorphic animal perception, or unknowable environments.
\end{abstract}

The organism unfolds into its ecology, but its ecology enfolds back into the organism; the organism is outside itself shaping its world, and its world is inside the organism shaping its body.

—Adam Robbert, "Earth Aesthetics" (2013)

Tano S. Posteraro is now at Penn State University.

Correspondence should be addressed to Tano S. Posteraro, Department of Philosophy, Penn State University, 228 Sparks Building, University Park, PA 16802. E-mail: tano.sage@gmail.com 
To begin, a brief sketch of the concepts at hand. The way an organism's environment gives itself over to that organism is an affordance. "The affordances of the environment are," in James J. Gibson's (1979/1986) own terms, "what it offers the animal, what it provides or furnishes, either for good or ill" (p. 127). This computer affords me the ability to render a digitized and coherent stream of thoughts. The floor affords me a surface on which to walk, the door a means by which to isolate myself. Ability and affordance are, however, inextricably linked. They are codefining, which "implies the complementarity of the animal and the environment" (Gibson, 1979/1986, p. 127). Word processing is a computational affordance only for organisms capable of operating a keyboard. An airplane can only offer itself as a means for transportation to organisms capable of purchasing tickets and reserving seats. These latter capacities determine the airplane's set of affordances. An airplane affords humans a means for transportation but only because they are, in the first place, capable of operating airplanes. It might afford birds the potential for high-altitude collisions. Its affordances vary relative to the capacities of whichever organisms relate with it. Ability and affordance are like sound and auditory system. One hears only the sounds one's ears are capable of registering. Affordances are tied to abilities, in other words, the way sounds are tied to their perception.

Affordances are defined by a relation between the features of a given environment and the capacities of a present animal. Climbability is, in the famous example, only an affordance of staircases for animals able to climb them (Cesari, Formenti, \& Olivato, 2003, pp. 111-124). Abilities, too, are defined by this sort of relation: in the absence of an affordance of climbability, no animal can climb. So the structure of organismic subjectivity, the relation between organism and environment, emerges out of a set of ability-affordance relations, each term of which is itself also a relation between organism and environment. Further, in order to foreground the dynamism of these relations, in order to think them developmentally, it is necessary to posit both their causal interaction over time and their causal dependency on, or entanglement with, one another (Chemero, 2009, p. 151). This dynamism comes in two temporal iterations: developmental and behavioral. "Over developmental time," in Chemero's (2009) words, "an animal's sensorimotor abilities select its niche-the animal will become selectively sensitive to information relevant to the things it is able to do" (pp. 150-151). And on a behavioral timescale, "the animal's sensorimotor abilities manifest themselves in embodied action that causes changes in the layout of available affordances" (p. 151). Most significant is, however, the processually reciprocal nature of this relationship: the way changes in a layout of affordances imply correlative changes in the way capacities are actualized. But this is nowhere near as straightforward as its proponents suggest, for, as Protevi (2013) indicates, "only the act of climbing a tree, not the unactualized ability to climb, can knock some bark off the tree or strain a muscle" (p. 151). 
The task, then, is first to understand both abilities and affordances as relations without rendering incoherent the claim that they causally interact over time and, second to trace the implications of this dynamic reciprocity for the genesis of organismic perceptual experience.

As my invocation of actualization suggests, the problem of relational causality is to be resolved by way of the metaphysical resources developed earlier. First, abilities ought to be conceived virtually. This resolves several puzzles in the cognitive-science literature: it relieves the tension Anthony Chemero (2009) sees between conceiving abilities, on the one hand, as "effectivities" (or potentialities) and, on the other, as possibilities prefigured prior to actualization without recourse to Chemero's own concept of function (p. 145). Abilities are inappropriately understood as possibilities precisely because they emerge out of a relation between animal and environment and are manifested only under specific conditions. In the absence of water, no animal can swim. Even in an encounter with water, being able to do so is a skill, one developed in certain circumstances and beholden to a set of conditions-even if those conditions include embryonic development. Bergson's (1975, p. 118) criticism is relevant here: to claim of a professional swimmer that her skill was possible before actual is to project the actuality of her ability backward, deprive it of reality, efface the process of its actualization, and conclude that it existed first as possibility.

Abilities are not possibilities. Their conception as effectivities emerges originally out of Robert Shaw's (2001) "Processes, Acts, and Experiences: Three Stances on the Problem of Intentionality." Abilities, for Shaw (2001), exist as biological (or, in some cases, technologically mediated) functions whose aim is to realize what he calls "the affordance goal" (p. 284). Shaw is, on this point, quite clear: "Effectivities," he writes, "always involve goal-directed biological functions" (p. 284). Because the goal in question is constrained by present affordances - that is, if an animal wishes to achieve higher ground, it must tarry with whatever pathways or climbable surfaces are available-effectivities come not only as the means to the realization of a goal but also more significantly as the necessary complement to present affordances. So, in other words, in order to realize a goal, a given animal puts one of its functions into play with a relevant affordance. Understood as effectivities, abilities are functions (i.e., in the sense that fingers function to grasp and hold), tied to affordances, aimed toward intentions or goals (i.e., in the sense that the function grasp can be aimed toward the goal grasp that branch). And, as such, they "transform possible experiences into potential ones and potential experiences into actual ones" (Shaw, 2001, p. 312). Put differently, before the advent of typewriters, it was possible for human fingers to type. Alongside their invention emerged the potential to type. Typing is a goal; that human fingers are functionally capable of complementing the requisite affordance allowed them by typewriters makes the act of typing potentially realizable. And, as fingers are marshaled in the 
right way on the keys of a present typewriter, that potential is transformed into the actual act of typing. Given the right conditions (the availability of a present typewriter, a set of working fingers, and the intention to type), the effectivity becomes an actual activity. This is, to reiterate, the tripartite structure of effectivities: (a) functions, tied to (b) affordances, aimed toward (c) goals. And this is the tripartite structure of their manifestation in activity: the presence of function indicates (a) possibility, the presence of a relevant affordance indicates (b) potentiality, and the relation between the two toward some goal brings potentiality into (c) actuality. This is Shaw. One need not, however, look much further for a weakness in this account than the fact that abilities are nowhere near so neatly predisposed (Turvey, 1992). Abilities, conceived as effectivities, Chemero (2009) argues, "when coupled with the right enabling conditions ... are guaranteed to become manifest" (p. 145). This is their unlikely neatness. Chemero is, I think, right to dismiss this conception on the basis that abilities are not so straightforwardly actualized, even under the necessary conditions. "Having the ability to walk does not mean," in his words, "that one will not fall down even in the ideal conditions for walking" (p. 145).

Chemero (2009) turns, however, illegitimately from a condemnation of effectivity toward an appeal to teleology. Claiming for abilities a status as "functions," he yokes them to a principle of normativity: "Individuals with abilities are," he writes, "supposed [emphasis added] to behave in particular ways, and they may fail to do so" (p. 145). If functions are not inevitably predisposed, they are, however, monotonously or singularly so-and for that reason they also fail to do justice to the indeterminately pluralistic nature of unexercised abilities.

Let us bracket for now the ontological status of unexercised abilities and their relation to affordances. In order best to account for this status, I introduce a philosophical distinction (taken from French philosopher Gilles Deleuze, 1994) not between actual and potential but between actual and virtual. Let me explain what I mean before reapproaching the issues delineated earlier.

It is easiest to begin by setting the virtual against what it is not. The virtual is real but not actual. It precedes the actual, at least in concept, but does not resemble or prefigure it. The virtual is not the possible. Neither is it appropriate to speak straightforwardly of the virtual as potential. The virtual is real without being actual the way a wooden desk's capacities to burn, splinter, expand, or crack are real without being actual. Before it is set aflame, the desk's capacity to burn exists but in unexercised form. Borrowing a terminological distinction from Deleuze's Logic of Sense (1990), the desk's capacities are better described not as existing but insisting (p. 81). They are not currently actual, but in different conditions, they tend toward actualization; they insist. Capacities exist as if on a spectrum of insistence: submerged in water, the desk's capacity to catch fire is especially far from becoming actual. Its capacities to expand, warp, and eventually decay are, on the other hand, a lot nearer actualization. The virtual is 
not, therefore, a simple inverse of the actual: one reaches the level of virtuality neither by depriving the actual of its reality nor by subtracting from it its concrete existence.

Although initially it may seem intuitive to speak of virtuality as possibility, doing so effaces both the degree to which capacities can insist into actual existence and the fact that, prior to the advent of their actualizations, virtual capacities do not resemble their concrete manifestations, unlike possibilities. To sharpen this point, it is worth looking to Henri Bergson's (1975) critique of the possible. "The possible," writes Bergson, "is only the real with the addition of an act of the mind that throws its image back into the past once it has been exacted" (p. 118). In order to arrive at the possible, we start, in other words, with the real, with what already exists. We subtract from it its existence, project its image backward, and proclaim that it existed first as a possibility subsequently "realized" in the real. The process of this realization is subject, however, to the rule of resemblance-which is to say that the real is supposed to resemble the possible, to be actualized in its image. But, to borrow a line from Daniel Smith (2009), "if the real is supposed to resemble the possible, is it not because we have retrospectively or retroactively 'projected' a fictitious image of the real back into the possible?" (p. 26). Exactly so. It is not the real that resembles the possible but precisely the opposite: the possible is formed in the image of what already exists. It is a purely negative concept, a negation of the actuality that it is supposed to found. The virtual is, however, both real and nonactual. And it is for this reason that the language of possibility is not adequate to the task of accounting for capacities, tendencies, and relations that are not actual, that do not resemble the actual, and that are furthermore differentiated from each other as well as from their actualizations.

If it does not suffice to speak of the virtual in terms of possibility, then it is equally misguided to attribute to it the status of potential. This is because potentiality is defined either by its telos, the purpose or end to which it is always oriented, or by an identity to its actual exercise (as is the case with possibility). I take it that potentiality canonically refers to Aristotle's (1995) conception of the term. To say, then, that it is misguided to speak of the virtual as the potential is to say that the virtual is decidedly non-Aristotelian. "We speak of perceiving in two ways," writes Aristotle, "for we say that something sees or hears both in the case of something that has the potentiality for seeing or hearing, even though it is asleep at the time, and in the case of something that is actually seeing or hearing at the time" (p. 188). This is, then, the identitarian distinction-a distinction that privileges identity at the expense of difference- between potential and actual: the closed eye sees potentially, the open one, actually. Potentiality therefore refers, in the first sense, to the horizon of identity a dormant capacity shares with its actual manifestation. Although the difference between possible and actual is one of existence, understood in this way, potential differs from actual only in terms of 
employment, application, or exercise. And yet, to take a line from Protevi (2013), the virtual emphatically "does not resemble its actualization; there is nothing identical in its being — it is fully differential" (p. 143). But, afforded a differential definition, potentiality falls prey instead to the snare of teleology. Taking as a model the way we speak of knowledge, Aristotle (1995) distinguishes two ways by which potentiality is actualized. We say, in one sense, that "a man knows because man is a kind of thing that knows and has knowledge," and, in another, that a man "who has grammatical knowledge knows" (pp. 189, 25-26). To know the rules of grammar is to harbor an identitarian potential for knowledge; it is to already have the knowledge that demonstration or explanation actualizes. "But in the first case," Aristotle continues, "we [pass from potential to actual knowledge] by being altered through learning, and by frequent changes from the contrary state" (p. 189). This is potentiality freed from the strictures of resemblance, for "alteration" and "frequent change" denote a difference between the potential for knowledge and its actual products. But this difference comes at the expense of an invocation of teleology: we are, no doubt, altered in the process of learning, but this is an end-directed change; it is guided, and its aim is present already before learning occurs. If the subject has, in other words, the potential to know before learning, this is because the acquisition of knowledge "is," for Aristotle, "a change into possession of a state and into the fulfillment of the subject's nature" (p. 189). This state is not prefigured before its actualization (as in identitarian potentiality), but the potential for its possession is nevertheless oriented toward it. This conception of potentiality is one of what I call monotonous disposition, for it conceives potential as state specific. I use the term "monotonous" not to denote a lack of interest or excitement but in its etymological sense: from the Greek monotonos, "of a single tone or sound" (Harper, 2013). The potential for a state—say, for having read Nietzsche's (1995) Thus Spoke Zarathustra-is, on this account, the specific capacity to attain that state, a capacity structured by a singular disposition toward it. But this is emphatically not the case for the virtual. The virtual is neither identitarian nor teleological. It is not structured in terms of resemblances or monotonous dispositions.

The virtual is, now speaking positively, a differential field whose dispositions vary relative to the specific conditions under which actualizations take place. As such, the virtual counterpart of the state-specific potential to read Zarathustra is a differential set of relations between capacities-say, between literacy of a sufficient degree, access to the necessary resources, free time, literary interest, and so on-that together constitute a "problematic field" the resolution or actualization of which may be, in certain conditions, a person's having read the book. But this field neither prefigures that state nor does it tend monotonously toward it. To take this example seriously, consider Little Miss Sunshine (Faris \& Dayton, 2006). Dwayne Hoover, one of the film's central characters and a classically miserable teenager defined by his existential malaise, is in one scene shown with a copy 
of Nietzsche's Thus Spoke Zarathustra. Dwayne seems sufficiently literate, he spends a lot of time alone, and he longs for a life of value. This particular conjunction of factors and circumstances makes likely a turn to Nietzsche. But if he finds Zarathustra's prose difficult, if Nietzsche's aphorisms do not open up before him, he might just as well turn instead to Camus. He might opt for the catharsis of music or painting. He might resolve his restlessness in the pursuit of a love interest. It is clear, in other words, that if Dwayne does decide to take up the task of reading Nietzsche's epic, it will not be because he harbored from the beginning a potential to attain the state of having read it, whether that potential is understood as an unactualized possibility, a dormant capacity, or a monotonous disposition. Conversely, if Dwayne reads the book, it will be because his literacy, his malaise, his aspiration, and his free time (among various other factors and conditions) together constitute a "problematic field" resolved by the actual act of reading Zarathustra. No one condition resembles, prefigures, or tends monotonously toward the state of having read Nietzsche. Further, no condition is on its own sufficient to account for the manifestation of that state. Neither, however, does the conjunction of all of them result inevitably in the state of having read the book. It is for this reason that, beyond a differential and ateleological structure, the virtual is also defined as a problem-or, more accurately, as a set or series of problems.

If it makes sense to speak of the problematic nature of virtuality, it is because the advent of an actualization is best understood as the creativity of a resolution or response. But problems do not for this reason preexist their solutions; they are immanent to each other. This is the key to virtuality: problem and solution coemerge in a single movement. Put differently, processes of actualization structure the problematic fields they resolve. Consider again Dwayne's interest in Nietzsche. The process of reading Zarathustra determines the elements whose relations comprise the problem at hand: literacy, existential unrest, free time, philosophical ability, and so on. When literacy or the process of learning to read is itself the solution, then the problem it resolves is structured in terms of cognitive condition, perceptual ability, access to educational resources, patience, and so on. Problems are therefore nested, fitted one inside the other, together constituting an expansive virtual terrain. One and the same solution can come in response to two widely divergent problematic fields, whereas one and the same problematic field can resolve itself in two widely divergent solutions. Just as literacy is both an element in the problematic field resolved by the process of reading Zarathustra and the resolution of a problem of its own, so too do the elements of that field come as resolutions to still more distant problems. And it is the process of learning to read that assembles a web of relations linking cognitive capacity to an access to educational materials, a familiarity with language, and so on. Dwayne cannot read Nietzsche without setting a network of elements into relation with each other and thereby constructing a 
problematic field. The process of reading the book is therefore made possible on the basis of a problematic field constructed in the very process of resolving it.

Virtual problems are structured in terms not only of a relation of elements but also by a specification of what I call singularities that are internal to each. Singularities are thresholds. Every particular board of wood will, for example, crack under a certain amount of weight. This "sensitive point" or threshold is specific to the board in question. Different people can tolerate different intensities of pain before flinching, different intensities of melancholy before crying, different volumes of toxic material before falling ill. These singularity thresholds emerge out of relations with other elements, as in the case of the threshold between my sickness and health, a sensitive point crossed only in contact with bodies outside of me. And they can change, "as in the case of land that is over-farmed by one crop, becoming barren for that crop or taking on capacities to support other crops" (Bryant, 2012). The elements of a given problem therefore already contain their own singularities or points of sensitivity and alteration, but it is the solution at hand that specifies their relevance. Each of a problem's elements must surpass a threshold specific to it in order to make possible its resolution: Dwayne's literacy, ambition, and philosophical capability must reach singularities internal to each if he is to succeed in reading Nietzsche. If he is, for example, lacking in ambition, the foreboding prose may push him in the direction of an easier writer. If his literacy does not meet a certain threshold, he may abandon his aspirations entirely, opting instead for a less demanding interest.

To clarify what I mean by the creative gap between virtual and actual, take, for example, the difference between education system and prison complex, two incarnations of disciplinary virtuality. There is nothing prisonlike in this virtual problem. Nor is there anything in it resembling a school. Instead, the problem "contains only the relations and singularities into which a human population to be controlled is put: corporeal distance, succession of exercises, precision of movement, degree of obedience to command, and so on" (Protevi, 2013, p. 10). The prison actualizes these elements in terms of a high degree of control, intolerance for defiance, a systematically regimented schedule, the restriction of bodies to cells or small rooms, and so on. A school actualizes the same elements to a lower degree of intensity of control: bodies are still restricted to specific spaces, movement is still regulated, obedience is still expected, but defiance is met with a difference in grade or a note home, not solitary confinement or corporal punishment (or so one hopes).

The intensive processes by which the problem comes to be individuated in an actual structure refer to changes in the singularities at play in each element. If teachers began handcuffing students to their desks during class time, what was first a school would rapidly fade into something closer to a prison. 
This change represents an intensification in degree of control, a shift in the singularity of one element of the problem (assuming, of course, a threshold between vocal suggestion and physical restraint corresponding, at least in part, to the difference between school and prison). Further, these virtual structures are not static: their elements are dynamic, the relations between one and another constantly shifting. A proliferation of less tolerant teachers represents a change in a school's restriction of the movement of its students just as it embodies a shift in the intensity of an element of the disciplinary problem.

So much for philosophical elucidation. Armed with this conceptual distinction, let us now turn back toward the ontological status of unexercised abilities and the dynamic nature of their relations with affordances. If abilities are to be understood as virtual, as I suggest they are, it is because they come as resolutions to tensions or problems that are latent in differential fields. ${ }^{1}$ Climbing is the exercise of an ability to the extent that it resolves (or integrates) a "fully differentiated neuro-somatic-environmental web" that neither resembles or prefigures the activity of climbing nor tends inevitably or monotonously toward it (Protevi, 2013, p. 143). The unexercised ability to climb exists as a distributed field of relations between a given animal's body (the somatic), its perceptualsensorimotor system (the neural), and various details of its environment. This is what it means to say that, like affordances, abilities are relations, not because the animal needs a staircase to climb in order to exercise the ability it has to do so but because that very ability emerges out of (while at the same time bringing together) a network of differential elements, a problematic field. And, to reiterate, each element of a virtual problem fluctuates in tune with changes in the others, implying a difference in actualization: given a staircase of a larger size, a climbing animal's legs must be longer, its muscles stronger, its will to climb greater than might be necessary for a smaller staircase. The activity of climbing is a resolution, a creative response to a problem structured in accordance with the animal's body and its environment. Given that problem, the exercise of an ability in response is creative to the extent that it comes always as one option among an array of many (Bryant, 2008, p. 154). Although certain solutions, the manifestation of certain abilities, insist more so than others, the advent of any one of them is never inevitable.

Problematic fields are nested, scalar: the staircase's height, an element in the problem resolved in the act of climbing it, is itself the resolution of another problematic field entirely. The staircase is, however, not an ability but an affordance. It is no surprise, then, that affordances too ought to be conceived as

\footnotetext{
${ }^{1}$ It is perhaps worth noting here that Shaw (2003) does invoke a language of virtuality but only in reference to ideas, images, or memories (p. 101). In that sense, to say that the ability to climb is virtual would be to say that it exists first as an idea or internal mental intention to be externalized in the actual act of climbing. This is emphatically not the case for the present position.
} 
virtual. Doing so does, as I already indicated, make possible an analysis of the causal relations they share with abilities; it also resolves the question of how affordances can exist independent of the animals that perceive them. Animals do not project affordances or features of environmental meaning onto an indifferent, unknowable world. Even with my back turned, the climbability of my staircase persists no less than does my capacity to climb it. Further, the properties that together afford climbability existed before the dawn of human consciousness and may, hypothetically, even outlive it—which is all just to say that affordances are real. But, like capacities, they are only actual under certain conditions. No staircase can afford climbability if all the animals capable of climbing it ceased to exist, but that affordance does not surge into existence alongside the lives of the relevant animals; rather, those animals actualize the affordance. Prior to its actualization, the affordance exists (or insists) virtually. This is a claim the implications of which are far-reaching and seldom appreciated. Chemero (2009) holds that it makes necessary a nuanced ontological realism, one that ties the subject to its world and situates experience somewhere between the two. This ontology is, as I aim to demonstrate, best understood in terms of virtuality.

Affordances do exist prior to, and in the absence of, the presence of animals capable of perceiving them. Affordances exist not as prefigured identities but as meshworks of differential relations. These meshworks are resolved (or individuated) into concrete affordances by the local perception of appropriately capable animals. Affordant actualization repeats the actualization of capabilities because the mechanism is, in each case, identical. The unactualized environmental affordance climbability exists first as the same distributed field of relations resolved in the act of climbing. To afford climbability, a staircase must be climbable. To be climbable, there must exist animals capable of perceiving in it that affordance. This is not, of course, to suggest that affordances come into existence, as if out of nothing, only as they are interacted with. No, they are emphatically animal independent, but in what that animal independence consists, or what it means to ascribe an animal-independent reality to the affordance, is that prior to the resolution of its virtual field the staircase is structured in such a way that, were the right animal present, it would afford that animal climbability. It insists before it exists in precisely the sense that the tendency a piece of wood has to burn insists into existence under the right conditions. This is, again, what it means for Gibson (1979/1986) to say that the essential relationality of affordances "implies the complementarity of the animal and the environment" (p. 127). In the same way, animals are capable of climbing to the extent that their bodies are structured in such a way that, were the right affordance present, they would be able to climb. Implicit in the structure of each is a relation between organism (body) and environment (layout).

Experience (or sensorimotor action) happens between the two, simultaneously actualizing an affordance as it expresses an ability, effectively tying together 
subject and world, organism and environment. Or, in Alva Noë's (2004) phenomenological description,

Experience isn't something that happens in us [that is, in the subject]. It is something we do; it is a temporally extended process of skillful probing. The world makes itself available to our reach. The experience comprises mind and world. Experience has content only thanks to the established dynamics of interaction between perceiver and world. (p. 216)

Interestingly enough, Noë invokes a language of "virtuality" to account for what perceptual content "manifests" as the subject explores its world by means of its body. He does so, however, without the benefit of the ontology of the virtual that I have described throughout the article and so falls frequently back into the trap of conceiving the virtual as the possible or potential, forcing it into a structure that inappropriately mirrors the actual. To modify Noë, then, the "dynamics of interaction" need to be conceived intensively, relative to the singularities in each element of a neuro-somatic-environmental field. Different organisms actualize different affordances out of the same physical layouts. Certain spiders can, for example, walk along the surface of a pond inside of which fish breathe, bacteria replicates, and frogs drown. Organismic ability therefore operates as an intensive individuation that actualizes an environmental affordance relative to the organism (and ability) in question. And the apparatus of each individuation therefore varies along with a given ability-affordance couple. In interacting with its environment, the organism does not merely recognize a set of affordances but also individuates and actualizes them. The mechanism of this individuation is emphatically not, however, simply hylomorphic: perception does not impose itself on a formless and inert matter. There is form (which is to say, affordance) already there, insistent on the virtual level, prior to the advent of organismic activity (Noë, 2004, p. 105). It is in precisely this virtuality that the reality of affordances consists: they do not exist (actually) so much as they insist (virtually); it is the organism that guides them into actuality.

Changes in any one element of the able-affordant field imply corresponding changes in the others, both in the virtual field and in its actual counterparts. These changes and interactions take place first, it is true, on the level of the actual. The animal's ability to climb only impacts the layout of its environment when exercised. "It is," in Protevi's (2013) words, "only these individuated actions that can change the web of relations structuring the intensive processes that integrate differential fields and produce action" (p. 152). There are two claims at work here: first, that the exercise of an ability is the actualization of a virtual field of relations, and second, that this field is comprised of elements impacted by actual activity. The actual not only individuates the virtual but in so doing also lets other potentialities insist to different degrees. Now, given that able individuations 
refer back to virtual affordances - and that the manifestation of affordances necessitates the presence of abilities - changes in the actual, whether somatic or environmental, correspond to reorientations in the layout of the virtual fields they resolve. Changes to these fields manifest as changes both to organismic capacity and to the environmental affordances that complement them. Thus, when actual organismic activity means an impact in the physical layout of an environment (as when a species alters its niche over evolutionary time), those changes reorganize the virtual field individuated in that activity. A different virtual field means a corresponding change in actual activity. Thus, the causal relation runs from the actual, through the virtual, and back.

Causal relations span both developmental and behavioral timescales. Developmentally, animals develop selective sensitivities, in tune with their sensorimotor abilities, to relevant environmental features in a niche (Chemero, 2009, p. 150). A niche is, in Chemero's (2009) words, "the set of situations in which one or more of its abilities can be exercised" (p. 148). "This collection of situations forms," he continues, "the organism's cognitive, behavioral, and phenomenological niche" (p. 148). ${ }^{2}$ The animal's niche will, in turn, "strongly influence the development of the animal's ability to perceive and act" (p. 150). The animal's activities alter its niche, and its niche influences the development of its abilities, affording certain possibilities and constraining others. Without delving too far into the minutiae of Niche Construction Theory, it is worth noting how organismic activity impacts the organism itself and therefore the future of that very activity. Post and Palkovacs (2009) take as an object of study two populations of guppies, observing the way differential patterns of predation lead to different populations in each, the implications of which include the fact that different patterns of excretion produce fluctuations in algae growth and potentially modify selection on guppy color through an increase in carotenoids derived from the algae (pp. 1629-1640). Although a change in color alone does not imply a corresponding change in ability, it requires no stretch of the imagination to conceive of a case that does. Consider, for instance, the way the activity of one organism alters the layout of affordances available to another. Earthworms are known to alter the makeup of the soil in which they live. A change in soil can mean a difference in selection pressure on local plants. Different plants mean different vegetal ecologies, different niches, and therefore a difference in the kind of sensorimotor abilities local organisms are able to manifest. Thus, in the very manifestation of those abilities, the layout of an organism's environment is changed, both for itself (the earthworm) and for others (species of plant).

On the developmental scale, this reciprocity is manifested in the operation of natural selection upon the genetic composition of a population of organisms rel-

\footnotetext{
${ }^{2}$ For a more sophisticated exposition of the niche, see Odling-Smee, Laland, and Feldman (2003).
} 
ative to its environment. And, in the words of Richard Lewontin (2000), "as that composition changes it forces a concomitant change in the environment itself. Thus organisms and environments are both causes and effects in a coevolutionary process" (p. 126). Put differently, as genetic composition changes, so too do the abilities of which organisms are capable; and as those abilities change, so too do the environmental affordances to which they correspond. Further, the way these rates of change are linked, the way genetic composition and environmental layout influence each other over time, is itself a temporal affair. In order to interact with a feature of its environment, in order to perceive an affordance, the timescale of a given organism must correlate with the timescale of that feature. Affordances are, in other words, temporally relative to the organisms with which they interact. A mountain, for example, can afford climbability only on sufficiently short timescales. Over geological time, its contours become viscous. Of this relativity, Manuel DeLanda (2002) writes,

the objective relativity of affordances with respect to temporal scales makes them the ideal candidate to define the "lived present" of a particular individual, that is, what this individual "perceives" within its own timescale as the relevant capacities of the other individuals [or environmental features] interacting with it. (p. 91)

As a consequence, the elements and relations that constitute the virtual problems that underlie abilities and affordances are themselves dynamic. Organismic ability therefore fluctuates in tune with rates of change in environments, species, and their coevolutionary interaction.

If the developmental relation between ability and affordances concerns the way organisms shape and are shaped by their environments in the activity of living, on a behavioral scale, an animal's activities "alter the world as the animal experiences it, and these alterations to the phenomenological-cognitivebehavioral niche, in turn, affect the animal's behavior and the development of its abilities to perceive and act ... and on and on" (Chemero, 2009, p. 152). What Chemero (2009) calls the phenomenological-cognitive-behavioral niche, I call the organism's practical field. Given the organism's functional concerns (say, swimming), its practical field is composed of those features (both able and affordant) salient for the ongoing navigation of its environment (i.e., the water). The organism has to coordinate its kinesthetic activity with changes in its practical field. Deleuze (1994) speaks of a "conjugation of singularities" that has to take place between one's body and the virtual field of water if one is to succeed in swimming. "Our real acts," he writes, "are adjusted to our perceptions of the real relations [in the practical field], thereby providing a solution to the problem [of how to swim]" (p. 165). In order to successfully negotiate a practical field, "the trick," writes Protevi (2013), "is to maintain the coordination of changes in the organism [the swimmer] with changes in the 
environment [the water]" (p. 152). It is to synchronize the rate at which what one can do changes- - how long can I hold my breath, how many strokes can I perform before needing rest, against how strong a current can I move, and so on-with changes in environmental affordances (strength of current, temperature of water). Behavioral and developmental timescales are related reciprocally. Indeed, developmental causality is itself constituted by the ability-affordance relations that occur on the behavioral timescales of individual organisms. Further, developmental changes constrain the way organisms behave practically. Abilities and affordances therefore causally relate in two temporal iterations, although each scale refers to the other.

In sum, somatic-environmental networks resolved in the manifestation of local abilities and affordances are reorganized by the actual interaction of organismic activity with environmental layout. The processes of this kind of reorganization occur beneath the structure of organismic experience-which is to say that physical features of the environment pressure selectively the physicality of an organism's body and that the activities of these bodies also organize and impact the development of the physical features of their environments. At bottom, abilities and affordances are sets of relations between, on the one hand, bodily structure and the way capacities to act can be actualized in a given environment and, on the other, the environment's physical features and the way those features are actualized relative to the activities of local organisms. The genetic condition for the emergence and development of animal perception is the experiential manifestation of a virtual field that links the animal with its world. And as these relations change, so does the structure of experience, the sensorimotor-perceptual abilities by which experience is defined. This organism is, as a consequence, relentlessly dynamic and tied at its foundation to the organization of its own world.

I have, in this article, brought to bear on the recursive, developmental meshworks of organismic ability and environmental affordance the concept of the virtual. Doing so allowed me to put the organism into motion, tying it dynamically to fluctuations in a neuro-somatic-environmental web individuated in concrete behavior and actual environmental layout. I recast the question of dynamic (ableaffordant) relationality as the question of actual-virtual reciprocity, displacing cognitive-scientific efforts to think the ontological status of affordances in the absence of the present perception of local animals. I temporalized the dynamism of these relations both behaviorally and developmentally, underscoring both the practical coordination an organism must maintain with changes in its environment and the way those changes affect, evolutionarily, the actualizations of the organism's own capacities and the way those actualizations contour the niches in which the organism lives. I hope, in the last analysis, to have demonstrated the utility offered to ecological psychology by a metaphysics of virtuality. 


\section{REFERENCES}

Aristotle. (1995). De anima. In T. Irwin \& G. Fine (Ed. \& Trans.), Selections (pp. 169-205). Indianapolis, IN: Hackett.

Bergson, H. (1975). The creative mind: An introduction to metaphysics (M. L. Andison, Trans.). Totowa, NJ: Littlefield, Adams.

Bryant, L. (2008). Difference and givenness: Deleuze's transcendental empiricism and the ontology of immanence. Evanston, IL: Northwestern University Press.

Bryant, L. (2012). On problems, multiplicities, regimes of attraction, and ethics. Larval subjects. Retrieved from http://larvalsubjects.wordpress.com/2012/05/19/on-problems-multiplicities-regimesof-attraction-and-ethics/

Cesari, P., Formenti, F., \& Olivato, P. (2003). A common perceptual parameter for stair climbing for children, young and old adults. Human Movement Science, 1, 111-124.

Chemero, A. (2009). Radical embodied cognitive science. Cambridge, MA: MIT Press.

DeLanda, M. (2002). Intensive science and virtual philosophy. London, UK: Continuum.

Deleuze, G. (1990). The logic of sense (C. V. Boundas, Ed., \& M. Lester, Trans.). New York, NY: Columbia University Press.

Deleuze, G. (1994). Difference and repetition (P. Patton, Trans.). New York, NY: Columbia University Press.

Faris, V. (Director), \& Dayton, J. (Director). (2006). Little Miss Sunshine. USA: Fox Searchlight Pictures.

Gibson, J. J. (1986). The ecological approach to visual perception. Hillsdale, NJ: Erlbaum. (Original work published 1979)

Harper, D. (2013). Monotonous. Online etymology dictionary. Retrieved from http://www.etymonline. com/index.php?term=monotonous

Lewontin, R. (2000). The triple helix: Gene, organisms, and environment. Cambridge, MA: Harvard University Press.

Nietzsche, F. (1995). Thus spoke Zarathustra (W. Kaufmann, Trans.). New York, NY: Modern Library.

Noë, A. (2004). Action in perception. Cambridge, MA: MIT Press.

Odling-Smee, J., Laland, K., \& Feldman, M. (2003). Niche construction: The neglected process in evolution. Princeton, NJ: Princeton University Press.

Post, D., \& Palkovacs, E. (2009). Eco-evolutionary feedbacks in community and ecosystem ecology: Interactions between the ecological theatre and the evolutionary play. Philosophical Transactions of the Royal Society of London B: Biological Sciences, 1523, 1629-1640.

Protevi, J. (2013). Adding Deleuze to the mix. In Life, war, earth: Deleuze and the sciences (pp. 137-152). Minneapolis: University of Minnesota Press.

Robbert, A. (2013). Earth aesthetics: Knowledge and media ecologies. Knowledge ecology. Retrieved from http://knowledgeecology.files.wordpress.com/2013/07/earth-aesthetics-8.pdf

Shaw, R. (2001). Processes, acts, and experiences: Three stances on the problem of intentionality. Ecological Psychology, 13, 275-314.

Shaw, R. (2003). The agent-environment interface: Simon's indirect or Gibson's direct coupling? Ecological Psychology, 15, 37-106.

Smith, D. W. (2009). Deleuze's concept of the virtual and the critique of the possible. The Journal of the Society for Philosophy and Literary Studies of Nepal: A Cross-Disciplinary Inquiry, 9, $34-43$.

Turvey, M. (1992). Affordances and prospective control: An outline of the ontology. Ecological Psychology, 4, 173-187. 